\title{
Speech therapy activity in a patient with traqueal amyloidose: a case report
}

\begin{abstract}
Introduction: Tracheal amyloidosis can be defined as the accumulation of fibrillar proteins, which can occur in any organ or tissue of the body.

Objectives: To present a case report of the speech-language intervention in a patient with tracheal amyloidosis.

Summary report: Case report of a 30-year-old male patient in an intensive care unit with altered cardiorespiratory parameters, requiring intubation. It presents a history of several procedures in the larynx since the age of 13, with a medical diagnosis of tracheal amyloidosis. It is tracheostomized, presents a large deviation in the larynx, which does not allow sufficient bronchial hygiene, besides the passage of nasoenteric probe for nutrition. Speech therapy team joins the case to enable and rehabilitate swallowing.
\end{abstract}

Conclusion: Deglutition and vocal therapy were performed, using a speech valve, allowing functional swallowing of the patient.

Keywords: amyloidosis, tracheal diseases, deglutition disorders, speech, language and hearing sciences, rehabilitation, tracheostomy, speech valve
Volume 4 Issue 4 - 2019

\section{Vanessa Souza Gigoski de Miranda,' Márcia Grassi Santana ${ }^{2}$}

IMultiprofessional Residency Program Intergraded in HealthEmphasis on Intensive Therapy, Universidade Federal de Ciências da Saúde de Porto Alegre, Portugal

${ }^{2}$ Preceptor of Multiprofessional Residency Program Intergraded in Health- Emphasis on Intensive Therapy, Irmandade Santa Casa de Misericórdia de Porto Alegre, Portugal

Correspondence: Vanessa Souza Gigoski de Miranda, Multiprofessional Residency Program Intergraded in HealthEmphasis on Intensive Therapy, Universidade Federal de Ciências da Saúde de Porto Alegre, Portugal,Tel 5I-984646363, Fax 51-32595161,Email vanessa_gigoski@hotmail.com

Received: June 13, 2019| Published: July 09, 2019

\section{Introduction}

The phonoaudiological care in the hospital, provides early diagnosis, and rehabilitation of swallowing disorders. This care, when directed to patients with respiratory diseases, contributes to identify possible causes or consequences of these pathologies, providing a reduction of hospital time and costs with these patients.

Tracheal amyloidosis can be defined as the accumulation of fibrillar proteins, which can occur in any organ or tissue of the body. Diagnosis requires histologic confirmation by biopsy. ${ }^{1}$ In the tracheobronchial presentation, amyloidosis is an idiopathic disease characterized by the deposition of fibrillar proteins in the submucosa of the trachea and bronchi. ${ }^{2}$ The most common symptom of amyloidosis in the laryngeal region is hoarseness, ${ }^{3}$ followed by dysphagia. ${ }^{4}$ The speech therapist is the professional specialized to rehabilitate dysphonia and dysphagia, identifying the importance of the insertion of the speech therapist in the multiprofessional team to act in cases of tracheal amyloidosis.

The following case describes the speech-language pathology in the rehabilitation of a patient with tracheal amyloidosis. Due to the rarity of the patient's underlying pathology, there is no description in the literature of speech-language pathology in similar cases. Also, it is important to present the therapeutic interventions used in this case, which as previously described, no interventions have been reported in the existing literature.

\section{Case description}

Case study performed after signing the Informed Consent Form, signed by the patient. The present work was developed following the precepts of the Ethics in Scientific Research according to resolution 466/12.

A 30-year-old male patient was hospitalized in a pneumological intensive care unit, with dyspnea, fever, desaturation, requiring nasotracheal intubation and the use of mechanical ventilation under controlled pressure. History of various procedures in the larynx since 13 years of age, with medical diagnosis of tracheal amyloidosis. In a 10-day period, 2 extubation attempts were performed, but the patient did not tolerate weaning protocols. Initially referred for tracheostomy. During withdrawal of the nasotracheal tube, the nasoenteric tube was removed. In Figure 1 we present RX of Thorax in which the deviation can be observed in the cannula of the patient's tracheostomy.

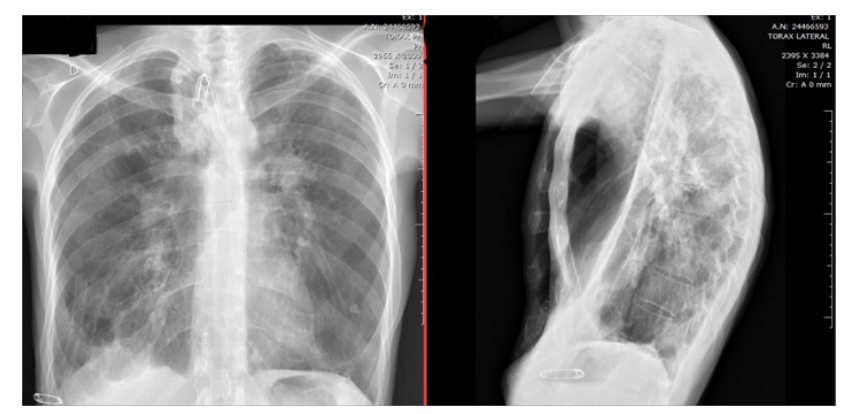

Figure I Rx of Torax.

After the tracheostomy was carried out, a speech-language evaluation was requested, since the patient remained without enteral nutrition, due to the difficulty in passing the enteral catheter due to the great deviation of the tracheal to the right, modifying the anatomy of the cervical region. In the evaluation, a patient with a cuff inflated in 100 millimeters of mercury and still with escape to the superior airway, lips sealed at rest, strength and mobility of preserved phonoarticulatory organs, swallowed saliva when requested, presenting reduced laryngeal elevation. Clinical evaluation of swallowing was carried out, with 3 milliliters of water in honey consistency, with blue food stain, alteration of cervical auscultation, and tracheal aspiration, secretion outlet with blue coloration. Due to the maintenance of the patient without enteral nutrition due to the 
impossibility of passing the probe, and the contraindication of oral feeding, we indicate gastrostomy.

Patient evolved in one week at weaning from ventilation, requiring only oxygen support. During this period, speech, speech and swallowing speech therapies were performed, as breath quality. After 10 sessions of therapy, the Passy Muir speech valve (PMV) was requested. In 4 days, the patient already has use of the PMV all day, with no signs of discomfort. We maintained vocal speech therapy, now with the possibility of reestablishing subglottic pressure and phonation, due to the benefits of the speech valve. After 7 sessions of speech therapy, clinical reassessment of swallowing was performed, with thickened liquid in the honey consistency, also with blue food color, without alteration of cervical auscultation, with no blue color in the aspiration of the tracheostomy. Direct swallowing therapy was started, in which the patient received about $20 \mathrm{ml}$ of thickened liquid at the honey consistency, twice a day, for swallowing training, associated with postural maneuvers.

After one week of direct swallowing training, videofluoroscopy of swallowing was requested in which normal swallowing was observed with pasty food and with thickened liquids. He presented silent tracheal aspiration with thin liquid. From the examination, together with findings from the clinical evaluation of deglutition, we adapted with the nutrition team a paste oral diet, with liquids thickened in the nectar consistency. The patient still uses the tracheostomy, for bronchial hygiene, and makes use of PMV. It feeds exclusively exclusively orally, and communicates through speech.

\section{Discussion}

Phonoaudiology works in the hospital environment with the rehabilitation of dysphagia, cognitive and communicative aspects. ${ }^{5}$ In the case described, the speech-language pathology from the intensive care setting provided evaluation and rehabilitation, even in the hospital setting of dysphagia and effective patient communication. The speech therapist must be a professional inserted in health services that value humanized care, since the process of humanization permeates communicative skills and attitudes that are the scope and intervention of the speech therapist, ${ }^{6}$ besides being essential for the adequate development of a multiprofessional work in intensive care units.

As one of the resources that the speech therapist can use, together with the team, in the hospital environment, we have the PMV. Such a device presents benefits already known as weaning from ventilation, improves the quality of swallowing and enables oral communication.? In the case reported, the patient was able to benefit from all the items that PMV could present to him. We identified PMV as an essential resource that has been present in intensive care units, allowing the weaning of mechanical ventilation, as well as reducing the length of stay in an intensive care setting, reducing hospital costs.
The studied pathology still presents few studies of the phonoaudiological aspects: communication and swallowing. In the current literature, we find the description of cases, ${ }^{2,8}$ but all of them are still very focused on individual physician intervention, without the multiprofessional approach that the case can be discussed, approached and treated.

The case addresses the speech-language pathology in a patient with tracheal amyloidosis, who could present prolonged hospitalization in the intensive care unit, given the complexity of the case. However, with $\mathrm{PMV}$, associated to speech therapies inserted in the multiprofessional work, the patient was discharged from the intensive care unit in 22 days, and in less than one month after, he was being orally fed. The importance of speech-language pathology in the multiprofessional team to support patients with tracheal amyloidosis is identified.

\section{Acknowledgements}

None

\section{Conflict of interest}

The authors declare no conflicts of interest.

\section{References}

1. Falk R, Comenzo R, Skinner M. The systemic amyloidosis. $N$ Engl J Med. 1997;13:898-909.

2. Silva LMC, Bellicanta J, Marques RD, et al. Amiloidose traquobronquica. J Bras Pneumol. 2004;30(6):581-584.

3. Pribitkin E, Friedman O, O'Hara B, et al. Amyloidosis of the upper aerodigestive tract. Laryngoscope. 2003;113:2095-2101.

4. Chadwick MA, Buckland JR, Mason P, et al. A rare case of dysphagia: hypopharyngeal amyloidosis masquerading as a post-cricoid tumor. $J$ Laryng Otol. 2002;116:54-56.

5. Ramos e Silva DL, Lira FOQ, Oliveira JCC, et al. Atuação da fonoaudiologia em unidade de terapia intensiva de um hospital de doenças infecciosas de alagoas. Rev CEFAC. 2016;18(1):174-183.

6. Gonçalves MJ. O significado da comunicação no atendimento ao paciente em UTI: como o fonoaudiólogo pode ajudar?. Mundo Saúde. 2008;32(1):79-84

7. Elpern EH, Borkgren Okonek M, Bacon M, et al. Effect of the Passy-Muir tracheostomy speaking valve on pulmonary. Heart Lung. 2000;29(4):287293.

8. Chatkin, Gustavo, Pipkin, et al. Amiloidose traqueobrônquica primária. Jornal Brasileiro de Pneumologia. 2008;34(7):528-531. 